\title{
Chromosomal Inversion
}

National Cancer Institute

\section{Source}

National Cancer Institute. Chromosomal Inversion. NCI Thesaurus. Code C6827.

A type of chromosome rearrangement in which a segment has been turned through 180 degrees (inverted), and inserted back into its orig inal location on the chromosome. 